\title{
Editorial: The African Evaluation Association 2019 Conference Edition
}

\begin{tabular}{|c|c|}
\hline \multicolumn{2}{|c|}{$\begin{array}{l}\text { Authors: } \\
\text { Mark Abrahams }{ }^{1} \text { @ } \\
\text { Kambidima Wotela } \\
\text { Michele Tarsilla }{ }^{3} \text { ( } \\
\text { Florence Etta }\end{array}$} \\
\hline \multicolumn{2}{|c|}{$\begin{array}{l}\text { Affiliations: } \\
{ }^{1} \text { Southern Hemisphere, } \\
\text { Cape Town, South Africa }\end{array}$} \\
\hline \multicolumn{2}{|c|}{$\begin{array}{l}{ }^{2} \text { WITS Graduate School of } \\
\text { Governance, Faculty of } \\
\text { Commerce, Law, and } \\
\text { Management, University of } \\
\text { the Witwatersrand, } \\
\text { Johannesburg, South Africa }\end{array}$} \\
\hline \multicolumn{2}{|c|}{$\begin{array}{l}{ }^{3} \text { UNICEF Regional Office for } \\
\text { West and Central Africa } \\
\text { (WCARO), Dakar, Senegal }\end{array}$} \\
\hline \multicolumn{2}{|c|}{$\begin{array}{l}{ }^{4} \text { GRAIDE International } \\
\text { Consultants, Lagos, Nigeria }\end{array}$} \\
\hline \multicolumn{2}{|c|}{$\begin{array}{l}\text { Corresponding author: } \\
\text { Mark Abrahams, } \\
\text { marka@iafrica.com }\end{array}$} \\
\hline \multicolumn{2}{|c|}{$\begin{array}{l}\text { How to cite this article: } \\
\text { Abrahams, M., Wotela, K., } \\
\text { Tarsilla, M. \& Etta, F., 2020, } \\
\text { 'Editorial: The African } \\
\text { Evaluation Association } 2019 \\
\text { Conference Edition', African } \\
\text { Evaluation Journal 8(1), a511. } \\
\text { https://doi.org/10.4102/aej. } \\
\text { v8i1.511 }\end{array}$} \\
\hline \multicolumn{2}{|c|}{$\begin{array}{l}\text { Copyright: } \\
\text { (c) 2020. The Authors } \\
\text { Licensee: AOSIS. This } \\
\text { is licensed under the } \\
\text { Creative Commons } \\
\text { Attribution License. }\end{array}$} \\
\hline \multicolumn{2}{|l|}{ Read online: } \\
\hline 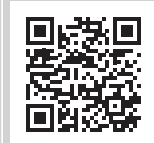 & $\begin{array}{l}\text { Scan this QR } \\
\text { code with your } \\
\text { smart phone or } \\
\text { mobile device } \\
\text { to read online. }\end{array}$ \\
\hline
\end{tabular}

The African Evaluation Association (AfrEA) is committed to developing and consolidating further rigorous and innovative evaluation knowledge and practices across the African continent. The dissemination of such knowledge is expected to inform the design and timely adjustment of development interventions implemented in multiple sectors and at different levels, be it a project, a programme and a policy. Furthermore, depending on the existing information needs and the degree of implementation progress of a given intervention, evaluation is ready to adapt itself in order to provide the most relevant and actionable answers to both strategic and operational questions. To this end, an evaluation could be formative or summative; it could focus on design or implementation modalities and processes; lastly, it could focus on and enhance learning and accountability amongst a variety of stakeholders. Thanks to the analytical thinking ascribed to evaluation, those who either developed or are implementing a policy, programme or project, could also learn what a results-chain or a theory of change should look like, how to link impact and outcomes based on evidence and how to relate them to the corresponding activities and inputs in a credible fashion. These and other contributions provided by evaluation to the development processes across the continent were discussed and made an integral component of the theme of AfrEA conference held in Abidjan in March 2019. This special AJE edition, which celebrates the Association's 20th birthday, is intended to feature some of the conference highlights on evaluation knowledge and practices across the continent.

As a reminder, the 9th AfrEA biannual conference was held in Abidjan in 2019, which focused on 'Accelerating Africa's Development: Strengthening National Evaluation Ecosystems', had five main objectives:

1. Support evaluations that contribute to real and sustained development in Africa.

2. Promote Africa-rooted and Africa-led evaluation through sharing African evaluation perspective.

3. Encourage the development and documentation of high quality evaluation practice and theory.

4. Support the establishment and growth of national evaluation associations or Voluntary Organizations for Professional Evaluation (VOPEs).

5. Facilitate capacity building, networking and sharing of evaluation theories, techniques and tools amongst evaluators, policymakers, researchers and development specialists.

Consistent with its objectives that intended to promote and advocate in favour of Made in Africa' evaluation approaches, the AfrEA conference aimed to empower its participants to influence national monitoring and evaluation policy and systems in their respective countries. Participants at the conference included Voluntary Organisations for Professional Evaluation (VOPEs), individual and Institutional AfrEA members as well as government and parliament representatives, development partners, members from civil society researchers, academia, the private sector and young and emerging evaluators. More than 200 articles were presented and other activities included panel discussions, poster presentations and workshops. An important outcome of the conference was the crafting of the AfrEA declaration. Such important endeavour was achieved in collaboration with the conference strand managers and shared at the conference closing ceremony as follows (see the given declaration):

- We, the members of AfrEA acknowledge and appreciate the tremendous work done by our presidents, boards, members voluntary organisations, institutions and individuals and other partners in fulfilment of the aims of AfrEA.

- We, the members of AfrEA, acknowledge the substantial progress made over the years in the commitment of the African Union and especially African parliamentary network on evaluation to the principles, tenets and practice of evaluation.

- We, the members of AfrEA, solemnly reaffirm and declare our commitment in the coming years to enable our members comprising individual evaluators, national evaluation 
associations, institutions, networks and partners to debate, analyse, disseminate and make constructive use of evaluation information, products and services for the betterment of Africa and the global community.

- We, the members of AfrEA, participants to the 9th AfrEA conference from 13 to 15 March 2019, and representatives of governments, parliaments, development partners, associations and networks and civil society of the African Evaluation Association declare and commit to continuing the following actions. The AfrEA website www.afrea.org has the full list of actions.

This Special Conference Edition of the African Evaluation Journal is part of the Journal's as well as AfrEA's commitment to debate, analyse and disseminate evaluative evidence in the interest of Africa and the global community. A total of 12 articles were initially submitted to the Journal for consideration and, despite great appeal and effort, very few French articles were submitted. After a preliminary screening and continued exchanges with the respective authors, nine of the twelve articles were accepted for the journal's peer review process. Six of these have since been accepted and the others will be considered for later editions. The first two articles discuss the legislative systems and functions and contribute to the vertex of governance (accountability, transparency and oversight) whilst the third is more on the outputs of the evaluation effort vis-à-vis governance. The last three articles serve as specific examples of this functionality at a micro level.

In the article, 'The evaluative role of legislatures in creating a responsive executive', Reitumetse Zantsi argues that the South African legislative sector is striving to make itself more effective so that it is proactive and responsive. Inherently, it needs to institutionalise the monitoring and evaluation function to allow for evidence-based decision making. Although present, it is uncoordinated partly because the legislative context is complex. To fully institutionalise monitoring and evaluation within the legislature, Zantsi proposes (1) enhancing coordination and collaboration, (2) strengthening internal systems and process and (3) a consented effort to build an evaluative culture.

Building on Zantsi's article, Wilhelm Janse van Rensburg, Francois Vreÿ and Theo Neethling discuss 'Collecting evidence on the use of parliamentary oversight tools' using South Africa parliamentary oversight of its military as a case study. They find varying degrees of success in the use of internationally recognised parliamentary oversight toolssuch as external audit opinions, oversight visits, committee debates, in-depth parliamentary inquiries, written and oral questions-between 1994 and 2014. They argue that ineffective oversight stifles transparency and, therefore, governance in a supposedly democratic setting. Without such an evaluation we would not pick up that despite a solid democratic dispensation our governance is in trouble and needs adjustment.
Ishmail and Tully share with us their reflection of how the Western Cape Provincial Government has adapted, implemented and institutionalised the National evaluation system in their article entitled, 'An overview of the provincial evaluation system of the Western Cape Government of South Africa as a response to the evaluation of the National Evaluation System'. More generally, the authors point out the Province's aspiration for excellence in evaluations, perfecting the Provincial Evaluation Systems through continuous feedback in various formats. Specifically, the Province is pursuing evaluations driven by the need for evidence-based decision making, people-centred evaluations and a solid evidence architecture that supports the priorities of the Province.

In their article, 'Validating an evaluation school functionality tool' Margaret Roper, Leticia Taimo, Jennifer L. Bisgard, Katharine Tjasink share a process of validating evaluation tools that take context on board. This is with a backdrop of aspiring to use a context-specific assessment tool to determine the status of school functionality and its relationship to teaching and learning outcomes. Again this is an important governance trajectory. If we are going to encourage evidencebased decision making then we should ensure that the evidence itself is rigorous. They encourage the need to assess or reliability and validity in evaluation.

The article entitled, 'Use of the most significant change technique to evaluate intervention in promoting childbirth spacing in Nigeria' is a summative evaluation undertaken by Aisiri and colleagues to assess the immediate outcome of behavioural change communication intervention. It focusses on the demand and uptake of modern childbirth spacing. It concludes that uptake is low in the north-western Nigeria largely because of myths and misconceptions as well as religious and cultural beliefs. Another aspect of this article is to identify what beneficiaries consider as success factors in an intervention using the most significant change technique.

To conclude, the last article in French, authored by Rachidatou Compaoreé, Adja Ouédraogo, Halima Tougri, Ousmane Badolo and Séni Kouanda pertains to the mixed methods formative evaluation of a malaria pilot intervention in Burkina Faso. Intended to measure the effectiveness of rapid tests used for malaria diagnostic purposes, the article highlights the impact that contextual factors may have on implementation fidelity within the scope of a health intervention in both rural and urban settings. The article also shows how the attention paid to short-term effects (the conduct of training) may hinder not only the timely measurement of medium-short effects but also the close monitoring of implementation processes on the ground. As a result, whilst all health personnel involved in the project being evaluated have been duly trained on the administration of the new test, the implementation on the ground differed from what established in operational manual and the field 
supervision was rather limited, with inevitable repercussions, such as shortage of test supplies, deterioration of the available tests and non-enforcement of adequate environmental safety measures.

Book review: The African Evaluation Association celebrates new texts that provide guidance to practitioners and emerging valuators, particularly text that originate on the African continent. Donna Podems' book, Being an Evaluator: Your Practical Guide to Evaluation is reviewed by Barbara Klugman in a very open, honest and detailed sharing entitled Beware of 'but' - Donna Podems's Being an Evaluator. Barbara notes that, in the context of African evaluation, the author extends the issue beyond 'words' to surface challenges related to language - that even within English, what words mean differs across countries and continents, something she has learnt well as an American living in South Africa - that body language influences how people receive what you say, as does the tone with which you say it - that cultural meanings are hidden inside words and need to be collectively discussed and named. According to Barbara the book represents a significant contribution to the Made in Africa Evaluation Concept.

\section{Acknowledgements Competing interests}

The authors declare that they have no financial or personal relationships that may have inappropriately influenced them in writing this editorial. 